\title{
$\underline{\mathbf{P}-27}$
}

\section{Secondary Metabolites from Calophyllum Sclerophyllum Calophyllum Hoseii}

\author{
Shaari Daud*, Gwendoline Cheng Lian Ee, Emilia Abd Malek and Soek Sin Teh
}

Faculty of Sciences, Universiti Putra Malaysia, 43400 Serdang, Selangor, Malaysia; E-mail: shaari111@pahang.uitm.edu.my

Calophyllum spp have been known for their biological activities. This genus belongs to the Guttifereae family where are rich with secondary metabolites such as xanthones, flavonoids and coumarins. Our recent phytochemical study on the bark of Calophyllum sclerophyllum and Calophyllum hoseii has led to the isolation of six xanthones, one coumarin and one flavanoid. These compounds are macluraxanthone (1), trapezifolixanthone (2), rubraxanthone (3), thwaitesixanthone (4), dombakinaxanthone (5), osajaxanthone (6), calopolyanolide A (7) and catechin (8). We report here the structural elucidations of these compounds based on the basis of detailed 1D-NMR $\left({ }^{1} \mathrm{H},{ }^{13} \mathrm{C}\right.$ and DEPT) and 2D-NMR (COSY, HMQC and HMBC) spectroscopic analysis.

Keywords: Calophyllum, Xanthones, Coumarin, Flavanoid. 